\title{
Integration of 2-D hydraulic model and high-resolution lidar-derived DEM for floodplain flow modeling
}

\author{
D. Shen ${ }^{1,2,3,5}$, J. Wang ${ }^{1,2,4}$, X. Cheng ${ }^{3,5}$, Y. Rui ${ }^{1,2}$, and S. Ye ${ }^{3,5}$ \\ ${ }^{1}$ Jiangsu Provincial Key Laboratory of Geographic Information Science and Technology, Nanjing, Jiangsu, China \\ ${ }^{2}$ Department of Geographic Information Science, Nanjing University, Nanjing, Jiangsu, China \\ ${ }^{3}$ Changjiang River Scientific Research Institute, Changjiang Water Resources Commission, Wuhan, Hubei, China \\ ${ }^{4}$ Jiangsu Center for Collaborative Innovation in Geographical Information Resource Development and Application, Nanjing, \\ Jiangsu, China \\ ${ }^{5}$ Engineering Technology Research Center of Mountain Torrent and Geological Disaster Prevention of The Ministry of Water \\ Resources, Wuhan, Hubei, China
}

Correspondence to: J. Wang (wangjiechen@nju.edu.cn, wangjiechen@hotmail.com)

Received: 22 January 2015 - Published in Hydrol. Earth Syst. Sci. Discuss.: 13 February 2015

Revised: 9 July 2015 - Accepted: 25 July 2015 - Published: 18 August 2015

\begin{abstract}
The rapid progress of lidar technology has made the acquirement and application of high-resolution digital elevation model (DEM) data increasingly popular, especially in regards to the study of floodplain flow. However, highresolution DEM data pose several disadvantages for floodplain modeling studies; e.g., the data sets contain many redundant interpolation points, large numbers of calculations are required to work with data, and the data do not match the size of the computational mesh. Two-dimensional (2D) hydraulic modeling, which is a popular method for analyzing floodplain flow, offers highly precise elevation parameterization for computational mesh while ignoring much of the micro-topographic information of the DEM data itself. We offer a flood simulation method that integrates 2$\mathrm{D}$ hydraulic model results and high-resolution DEM data, thus enabling the calculation of flood water levels in DEM grid cells through local inverse distance-weighted interpolation. To get rid of the false inundation areas during interpolation, it employs the run-length encoding method to mark the inundated DEM grid cells and determine the real inundation areas through the run-length boundary tracing technique, which solves the complicated problem of connectivity between DEM grid cells. We constructed a 2-D hydraulic model for the Gongshuangcha detention basin, which is a flood storage area of Dongting Lake in China, by using our integrated method to simulate the floodplain flow. The results demonstrate that this method can solve DEM associated
\end{abstract}

problems efficiently and simulate flooding processes with greater accuracy than simulations only with DEM.

\section{Introduction}

Floodplain flow simulation is important for forecasting floods and assessing flood-related disasters. The typical focus of simulation studies is to predict accurate flood inundation extents, depths, and durations. In the field of hydraulic calculations, the building of one-dimensional (1-D) and two-dimensional (2-D) hydraulic models is a common method. In recent years, 2-D hydraulic models have emerged as a standard for predicting flood conditions not only in academic contexts but also in technical applications; thus, 2-D approaches have largely replaced 1-D approaches that, despite their efficiency and potential for improvement in compound channels, present conceptual problems when applied to overbank flows (Gichamo et al., 2012; Abu-Aly et al., 2014; Costabile et al., 2015).

Until the advent of survey technologies such as lidar, computational flood hydraulics was increasingly limited by the data available to parameterize topographic boundary conditions rather than the sophistication of model physics and numerical methods. New distributed data streams, such as lidar, now pose the opposite problem of determining how best to use their vast information content optimally within a compu- 
tationally realizable context (Yu and Lane, 2006a; McMillan and Brasington, 2007). With the availability of highresolution digital elevation models (DEMs) derived from lidar, 2-D models can theoretically now be routinely parameterized to represent considerable topographic complexity, even in urban areas where the potential exists to represent flows at the scale of individual buildings. Many scholars have tried to apply high-resolution lidar-derived DEM data to floodplain flow models and analyze the effects of different spatial DEM data resolution on model calculations (Sanders, 2007; Moore, 2011; Sampson et al., 2012; Meesuk et al., 2015).

With advances in the processing capacity of computers, hydraulic models directly based on meter-scale fine grid have been applied (Schubert et al., 2008; Meesuk et al., 2015). In some studies, the resolution of the computational mesh has even reached the decimetric scale (Fewtrell et al., 2011; Sampson et al., 2012), which has improved the performance of high-resolution DEM 2-D hydraulic models to some extent. Under such fine scales, the topography under bridges and all man-made features, such as buildings and roads, can be presented accurately in the computational mesh (Brown et al., 2007; Schubert et al., 2008; Sanders et al., 2008; Mandlburger et al., 2009; Schubert and Sanders, 2012; Guinot, 2012).

Unfortunately, the computational costs of 2-D flood simulation at scales approaching $1 \mathrm{~m}$ are very high, and it is not unusual to work with study areas of $100 \mathrm{~km}^{2}$ or more (Sanders et al., 2010). According to the research of Sampson et al. (2012), when using an extremely efficient 2-D code such as LISFLOOD-FP (Bates and De Roo, 2000), the domain size is approaching the limits of feasibility at $10 \mathrm{~cm}$ resolution, thus requiring $100 \mathrm{~h}$ on a high-performance cluster; in contrast, ISIS-FAST (Shaad, 2009) simulation over the same domain can be run 750 times within the same period (Sampson et al., 2012). Such models, which directly employ meter-scale, high-resolution computational mesh, are limited by large study areas. For example, the study area in the research of Sampson et al. (2012) covers $0.11 \mathrm{~km}^{2}$ (Sampson et al., 2012), and the study area in the research of Meesuk et al. (2015) covers $0.4 \mathrm{~km}^{2}$. Even where highly detailed topographic surveys are available, their direct use in highresolution grids may not be feasible for large-scale flood inundation analyses (e.g., events involving both rural and urban areas), both in terms of model preparation and computational burden (Dottori et al., 2013; Costabile and Macchione, 2015). Computational constraints on conventional finite-element and volume codes typically require model discretization at scales well below those achievable with lidar and are thus unable to make optimal use of this emerging data stream (Marks and Bates, 2000; McMillan and Brasington, 2007; Neal et al., 2009; Yu, 2010).

For raster-based 2-D models, sub-grid and porosity parameterization methods enable efficient model applications at coarse spatial resolutions while retaining information about the complex geometry of the built environment (Yu and Lane, 2006b; McMillan and Brasinton, 2007; Yu and Lane, 2011; Chen et al., 2012a, b). However, while these techniques can display surface features, the flexibility of the computational mesh for these raster models is not as good as that of unstructured grids such as irregular triangular elements. An unstructured grid allows one to modify the density of the grid points in accordance with the topographic features and expected hydraulic situations (Costabile and Macchione, 2015). Nowadays, most hydrodynamic-numerical models are solved using a finite-element or finite-volume approach on the basis of unstructured or hybrid geometries (Mandlburger et al., 2009).

To improve the computational efficiency of hydraulic models, parallel technology has been employed in hydraulic model calculations (Neal et al., 2010; Vacondio et al., 2014). However, this improvement on efficiency is still limited for enormous high-resolution DEMs when the technology is applied to large study areas (Costabile and Macchione, 2015); even so, computer cluster-based parallel computation is able to solve the problems caused by high-resolution DEM data when applied in 2-D flood simulation models (Sanders et al., 2010; Yu, 2010). The limitations of available computing resources, therefore, still restrict the applications where very detailed information or risk-based analyses are required over large areas (Chen et al., 2012b). There is a current need for suitable procedures that can be used to obtain a reliable computational domain characterized by the total number of elements feasible for a common computing machine.

Here, we propose a new flood simulation method that integrates a 2-D hydraulic model with high-resolution DEM data. Starting with high-resolution DEM data, we constructed a comparatively coarse computational mesh and then constructed a 2-D hydraulic model. The results of the 2D hydraulic model were overlaid with the high-resolution DEM data and the flood depth in DEM grid cells was calculated by using local inverse distance-weighted interpolation. During the process of interpolation, there can be many false flood areas in the DEM grid because parts of the grid cells are interpolated despite not being inundated. To remove false flooded areas, we marked all of the flooded areas using run-length encoding and then obtained the real flood extent through run-length boundary tracing technology, which is a method that saves much effort when verifying the connectivity between DEM grid cells. Lastly, we constructed a 2D hydraulic model for the Gongshuangcha detention basin, which is a flood storage area of Dongting Lake in China, and calculated the inundation extent and depth during different periods using our integrated method. By analyzing and comparing the results, we prove that this method can enhance the accuracy and reliability of floodplain flow modeling. 


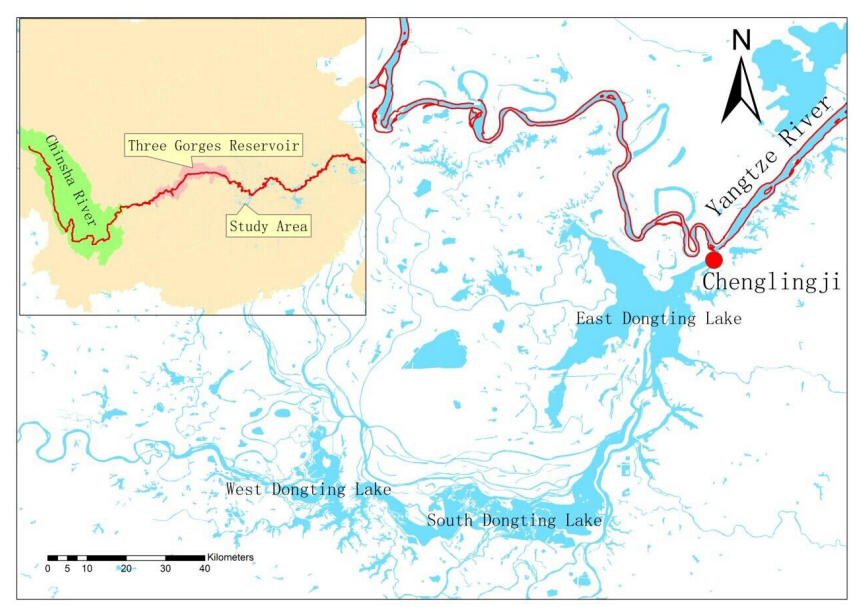

Figure 1. The location of Dongting Lake in the Yangtze River basin.

\section{Study area and 2-D hydraulic model}

\subsection{Study area and DEM data set}

Dongting Lake $\left(111^{\circ} 40^{\prime}-113^{\circ} 10^{\prime} \mathrm{E}, 28^{\circ} 30^{\prime}-30^{\circ} 20^{\prime} \mathrm{N}\right)$, with a total area of $18780 \mathrm{~km}^{2}$, is located in the middle reaches of the Yangtze River (Changjiang River; Fig. 1). The areas through which waters of Dongting Lake flow include the districts of Changde, Yiyang, Yueyang, Changsha, Xiangtan, and Zhuzhou in Hunan province as well as three cities in Jinzhou of Hubei Province. Dongting Lake is surrounded by mountains on three sides and its fountainheads are varied and complicated. It is a centripetal water system that fans out from the center. It only flows into the Yangtze River through Chenglingji of Yueyang (Fig. 1).

In the Changjiang River, a large flood occurred in 1860 and 1870, and the Ouchi and Songzi rivers burst their banks. During these events, floods flowed into Dongting Lake along with large quantities of sediment. Deposition of sediment has caused the rapid growth of the bottomlands and highlands, and some of the watercourses, lakes, and bottomlands have been reclaimed. Since then, Dongting Lake shrank from $4350 \mathrm{~km}^{2}$ in 1949 to $2625 \mathrm{~km}^{2}$ in 1995 (as measured by the Changjiang Water Resources Commission in 1995). The total lake area and spillway area is less than $4000 \mathrm{~km}^{2}$, about two-thirds of its former large size. Nowadays, Dongting Lake is commonly divided into the following three parts: East Dongting Lake, South Dongting Lake and West Dongting Lake, among which West Dongting Lake has the largest water area.

Because of its special location and complex river network system, this area is prone to frequent flooding. To protect local communities, numerous economic resources in the forms of labor and money have been spent on dike construction. A total of 266 levees have been built around the Dongting Lake area to prevent flooding, with a total length of $5812 \mathrm{~km}$, the largest levee is $3471 \mathrm{~km}$ in length and the second largest is

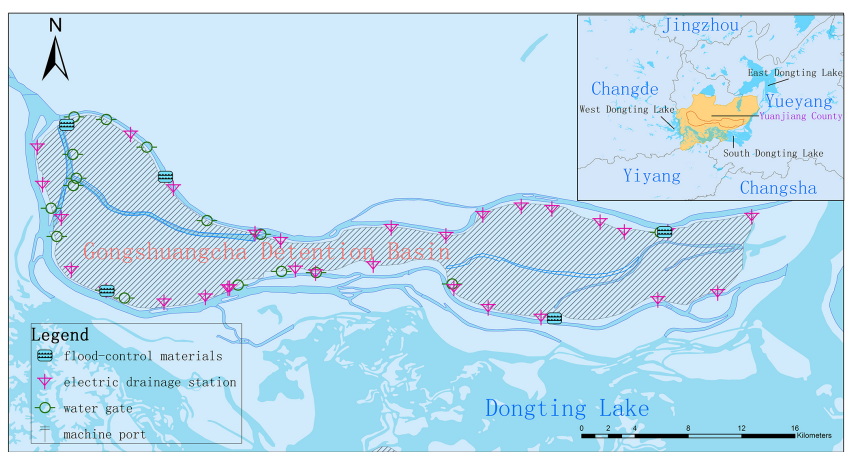

Figure 2. The location of the Gongshuangcha detention basin in the Dongting Lake area.

$1509 \mathrm{~km}$ in length. Flooding events in this area have caused significant destruction in the past. The costs of damage following individual events in 1996 and 1998 were CNY 15 and 8.9 billion, respectively. The pressure to prevent flooding and the associated damage has been a major factor affecting healthy economic development and living standard improvements in Hunan province.

Flood storage and detention areas, which are important to flood control and the mitigation of flood disasters in key areas, are critical components of a river flood control system. Specifically, effective basin flood control planning requires an understanding of the locations and characteristics of flood storage and detention areas in a region. Overall, planned flood diversions, which guarantee safety in key areas while bringing losses to some other areas, are reasonable and necessary. At present, there are 98 major flood storage and detention areas in China, which are mainly located in the middle-lower plain of the Changjiang River, Huanghe River, Huaihe River, and Haihe River. The Gongshuangcha detention basin, which is one of the largest dry ponds in the Dongting Lake area, is located in the northern part of Yuanjiang county, and it faces South Dongting Lake to the east and Chi Mountain to the west with water in between (Fig. 2). In total, the detention basin is characterized by $293 \mathrm{~km}^{2}$ in storage area, $121.74 \mathrm{~km}$ in levee length, and $33.65 \mathrm{~m}$ in storage height. It has a storage volume of $1.85 \times 10^{9} \mathrm{~m}^{3}$, and is home to 160000 inhabitants.

We employed the airborne laser-measuring instrument HARRIER 86i, from the German TopoSys Company to acquire aerial photography images of the Gongshuangcha detention basin from 1 to 8 December 2010. The digital camera we used was a Trimble Rollei Metric AIC Pro and the inertial navigation system was an Applanix POS/AV with a sampling frequency of $200 \mathrm{~Hz}$. The laser scanner used was the Riegl LMS-Q680i, with a maximum pulse rate of $80-400 \mathrm{KHz}$ and scanning angle of $45 / 60$.

By processing the point cloud data, we derived a highresolution DEM of the Gongshuangcha detention basin (Fig. 3). We checked the DEM data quality in terms of plane 


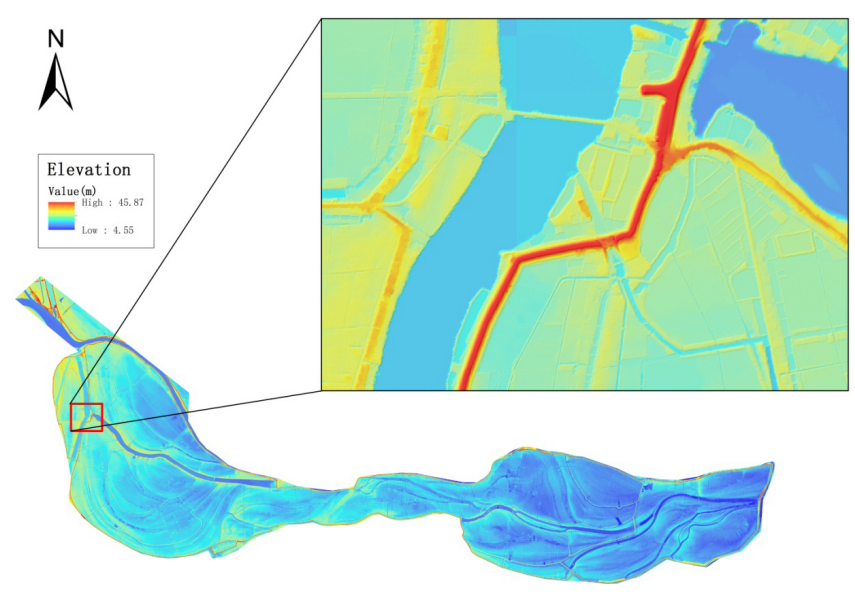

Figure 3. Digital elevation model (DEM) data $(1 \mathrm{~m}$ resolution) for the Gongshuangcha detention basin. Coverage shown is $50 \mathrm{~km} \times 20 \mathrm{~km}$; Spatial resolution of $1 \mathrm{~m}$; DEM grid is 22000 rows $\times 51000$ columns; and file size is $4.18 \mathrm{~GB}$.

precision and elevation precision, and the results showed that it could meet the application requirement. The DEM plane position was checked by global positioning system real-time kinematic (GPS-RTK) technology. After conversion parameters were set and control coordinates were confirmed, ground features' plane coordinates, such as the corners of buildings, high-tension poles, telecom poles, and road edges, were measured. We checked 20 ground feature points and the plane position mean square error was $0.44 \mathrm{~m}$. The DEM elevation was checked by class 5 leveling. Using an annexed leveling line or closed leveling line, we calculated the elevation of check points and compared them with a digital terrain model (DTM) and DEM. We checked 70 elevation points, and the elevation mean square error was $0.040 \mathrm{~m}$.

The spatial reference used was the Gauss-Krüger projection coordinate system with Beijing 1954 datum, and the elevation system was based on the 1985 national elevation standard, of which the lowest elevation is $4.55 \mathrm{~m}$ and the highest $45.87 \mathrm{~m}$. The general landscape shown in the DEM is flat, and much micro-topography information for levees, dikes, and ridges is retained (Fig. 3).

\subsection{2-D hydraulic model}

In 2008, the Changjiang Water Resources Commission approved a report titled the "Comprehensive Treatment Planning of Dongting Lake Area" (Changjiang Water Resources Commission, 2008). The report highlighted the serious threat posed by flooding, which could cause a surplus water volume of $21.8-28 \times 10^{9} \mathrm{~m}^{3}$ in the middle and lower reaches of the Yangtze River. It also stressed that the effects of the Three Gorges Project, which greatly influences the conditions for incoming water and sediments, must be taken into consideration. Even though the completion of the Three Gorges Project and the Xiluodu and Xiangjiaba dams on the Chin- sha River enhanced the region's ability to drain floods around Chenglingji (Fig. 1), at the confluence of Dongting Lake and the Yangtze River; the report emphasized that there is an urgent need to construct a $10 \times 10^{9} \mathrm{~m}^{3}$ diversion storage zone around Chenglingji.

According to the "Report on the Feasibility of the Flood Control Project of Qianliang Lake, Gongshuangcha and East Datong Lake of Dongting Lake Areas" (Ministry of Water Resources, 2009), flood waters from the events in 1954, 1966, and 1998, in Chenglingji could have been restricted to safely manageable levels if local detention basins were set up to divert $8000-12000 \mathrm{~m}^{3} \mathrm{~s}^{-1}$ of rising waters. For the 1954 flood event, the report shows that the maximum diversion should have been set at $10000 \mathrm{~m}^{3} \mathrm{~s}^{-1}$, with contributions from the Qianliang Lake detention basin $\left(4180 \mathrm{~m}^{3} \mathrm{~s}^{-1}\right)$, Gongshuangcha detention basin $\left(3630 \mathrm{~m}^{3} \mathrm{~s}^{-1}\right)$, and Datong Lake detention basin $\left(2190 \mathrm{~m}^{3} \mathrm{~s}^{-1}\right)$; the corresponding water levels for the dikes should have been set at 33.06, 33.10, and $33.07 \mathrm{~m}$, respectively.

According to the standard design of the Gongshuangcha detention basin diversion, we simulated flood flow using a mode controlled by sluice behavior. The resulting hydrograph acted as the input parameter, with flood flow into the sluice conditioned as follows: when the water level $(H)$ was below $31.63 \mathrm{~m}$, the flow volume into the sluice was $3630 \mathrm{~m}^{3} \mathrm{~s}^{-1}$; when $H$ was $31.63-32.60 \mathrm{~m}$, the flow volume was $3050 \mathrm{~m}^{3} \mathrm{~s}^{-1}$; when $H$ was $32.60-33.65 \mathrm{~m}$, another flow diversion exit was opened.

The flood routing model employed 2-D unsteady shallowwater equations to describe the water flow, and we used the finite volume method (FVM) and Riemann approximation solver to solve the coupled equations and simulate flood routing inside the detention basin. We used non-structural discrete mesh to represent the computational zone based on the landscape of the area and the location of water conservancy projects. Then to ensure accurate conservation, we used the FVM to decide the bulk, momentum and the equilibrium of density for each mesh element in different periods. To ensure precision, we used the Riemann approximate solver to calculate the bulk and normal numerical flux of the momentum between the mesh elements. The model solves the equations through FVM discretion and converts 2-D problems into a series of 1-D problems with the help of the coordinate rotation of fluxes. The basic principles are as follows.

1. Basic control equation. The vector expression of conservative 2-D shallow-water equation is as follows:

$$
\frac{\partial \boldsymbol{q}}{\partial t}+\frac{\partial \boldsymbol{f}(q)}{\partial x}+\frac{\partial \boldsymbol{g}(q)}{\partial y}=\boldsymbol{b}(q) .
$$

In this expression the conservative vector is $\boldsymbol{q}=[h, h u$, $h v]^{T}$, the flux vector of the $X$ direction $\boldsymbol{f}(q)=[h u$, $\left.h u^{2}+g h^{2} / 2, h u v\right]^{T}$, and the flux vector of the $Y$ direction $\boldsymbol{g}(q)=\left[h v, h u v, h v^{2}+g h^{2} / 2\right]^{T} . h$ is the height, 
$u$ and $v$ correspond to the average uniform fluxes of $X$ and $Y$ directions, respectively, $g$ is the gravity, and the source term $\boldsymbol{b}(q)$ is

$\boldsymbol{b}(q)=\left[\boldsymbol{q}_{\mathrm{w}}, g h\left(s_{0 x}-s_{f x}\right)+\boldsymbol{q}_{\mathrm{w}} u, g h\left(s_{0 y}-s_{f y}\right)\right]$.

In this expression, $s_{0 x}$ and $s_{f x}$ are the river slope and friction slope along the $X$ direction, respectively, $s_{0 y}$ and $s_{f y}$ are the river slope and friction slope along the $Y$ direction, respectively, and $\boldsymbol{q}_{\mathrm{w}}$ is the net depth of water in each time unit. The friction slope can be calculated through the Manning formula.

2. Discretization of equations. Calculate the basic FVM equation through discretization on any unit of $\Omega$ by the following divergence principle:

$$
\iint_{\Omega} \boldsymbol{q}_{t} \mathrm{~d} \omega=-\int_{\partial \Omega} F(q) \cdot n \mathrm{~d} L+\iint_{\Omega} \mathbf{b}(q) \mathrm{d} \omega .
$$

In this expression, $n$ is the normal numerical flux outside of unit $\partial \Omega, d \omega$ and $\mathrm{d} L$ are the surface integration and line integration, and $F(q) \cdot n$ is the normal numerical flux, where $F(q)=[f(q), g(q)]^{T}$. These equations demonstrate that the solution can convert 2-D problems into a series of local 1-D problems.

3. Boundary conditions. The model sets the following five kinds of flow boundaries: the Earth boundary, the outer boundary of slow and rushing flow, the inner boundary, the flowing boundary for no-water, and the water exchange unit and tributary boundary for wetlands.

4. Solution to the equation. The equations, which are explicit finite schemes can be solved through an interactive method over time.

The computational mesh of the 2-D hydraulic model for the Gongshuangcha detention basin (Fig. 4) was constructed by a non-structural triangular mesh in which there were 83378 triangles, each of whose side length was between 100 and $150 \mathrm{~m}$. On main levees, the model mesh was denser (each side length was between 60 and $80 \mathrm{~m}$ ). With the $1 \mathrm{~m}$ resolution DEM data, we obtained the elevation value of the mesh node and triangle center points through nearest interpolation, and set the values as the initial condition. The model computes the water level of each triangular mesh's central point every 10 min. Finally, it simulates inundation processes for 50 periods ( $8 \mathrm{~h}$ and $20 \mathrm{~min}$ in total).

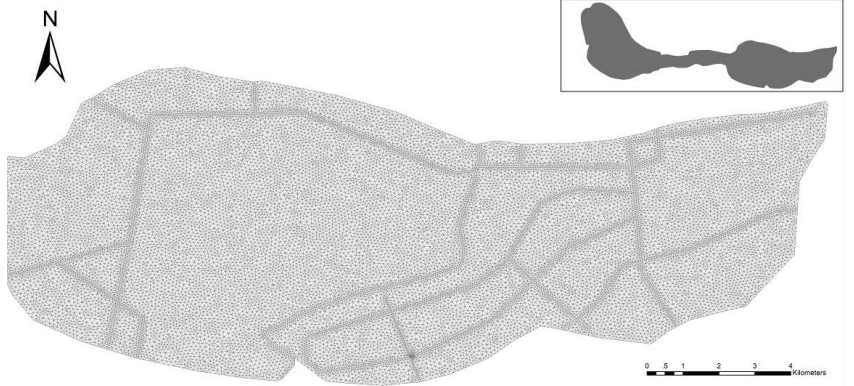

Figure 4. The two-dimensional (2-D) hydraulic model mesh of the Gongshuangcha detention basin and its regional enlarged view.

\section{Methodology}

\subsection{Local inverse distance-weighted interpolation}

With high-resolution DEM data, it is not precise to give the floodwater level for the whole DEM grid cells in the mesh element directly because the actual elevation value of each cell in the DEM grid is different. One reasonable way to accomplish this is to calculate the water level of every DEM grid cell through spatial interpolation technology like 1-D hydraulic modeling. There are some common spatial discrete water-level point-based interpolation methods for flood water level including inverse distance-weighted interpolation (Werner, 2001; Moore, 2011) and linear interpolation (Apel et al., 2009). Some of the discrete points interpolation techniques are based on natural neighbors because of their comparatively better performance in evaluating terrain changes; they also have quite obvious advantages in flood level interpolation (Sibson, 1981; Belikov and Semenov, 1997, 2000; Sukumar et al., 2001). Inverse distance-weighted interpolation is a comparatively simple way to get the spatial interpolation data, and it interpolates the values of unknown points given the locations and values of known points. In a highresolution DEM, we can obtain a water-level value for each central point of every DEM grid cell through interpolation, and compare the water-level value with the elevation value of the DEM grid cell. If the water-level value is higher than that of the DEM grid cell, it means this grid cell is inundated. The inundation depth of the DEM grid cell is the water-level value minus the grid cell elevation value.

It is very important to choose computational mesh nodes as the known interpolated points for the water-level interpolation of DEM grid cells because it is improper to get all the nodes in a hydraulic model involved in water-level interpolation when tens or even hundreds of thousands of computational mesh nodes are involved. Figure 5 shows a nonstructural modeling computation mesh (triangulated irregular network, TIN). The computational water-level value of the model can be located on the central point of every triangle (as $\mathrm{C} 1-\mathrm{C} 13$ shows) or on the node of the triangles (as $\mathrm{P} 1-\mathrm{P} 12$ shows) according to different solutions of the equa- 


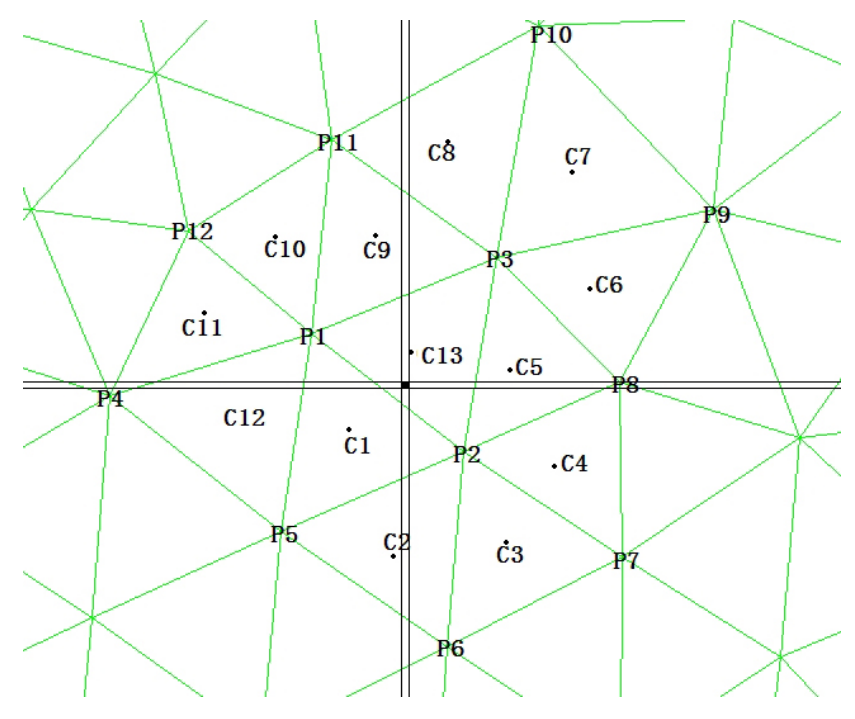

Figure 5. The scheme of spatial interpolation.

tion. For the cell located at row $I$ and column $J$ of the DEM grid, we can decide the location of the cell by the spatial coordinate of the central point. If a DEM grid cell (the black square) is inside P1P2P3, the following methods can be used to choose the nodes for water-level interpolation.

First, obtain the coordinate and its water-level value for the central point $\mathrm{C} 13$ of P1P2P3. Then search all the triangles that share the nodes P1, P2, and P3 with P1P2P3, and calculate the coordinate of the central points of these triangles (C1-C12) and their water-level values. The equation for the water level of the grid cell at row $I$ and column $J$ is expressed as

$z(x)=\frac{\sum_{i=1}^{13} z\left(C_{i}\right) \times \mathrm{d}_{i x}^{-2}}{\sum_{i=1}^{13} \mathrm{~d}_{i x}^{-2}}$.

In this equation, $x$ stands for the central point which is located at row $I$ and column $J$ of the DEM grid, $z\left(C_{i}\right)$ is the water-level value of the $\mathrm{NO} i$ known point, $\mathrm{C}$ is the central point of the triangle, and the distance between each pair of $\mathrm{NO} i$ known point and grid node $x$ is represented by $d_{i x}$ raised to the power $r$, which is set to 2 for spatial data interpolation.

The method mentioned above can interpolate the inside of the actual flood extent. As the water-level elevation of all the known points that are calculated in local areas are equal to the DEM grid cell elevations, values for DEM grid cells that are not inundated can be determined without interpolating, which reduces the number of calculation needed. This method can also be employed for other kinds of computational grids such as quadrilateral grids.

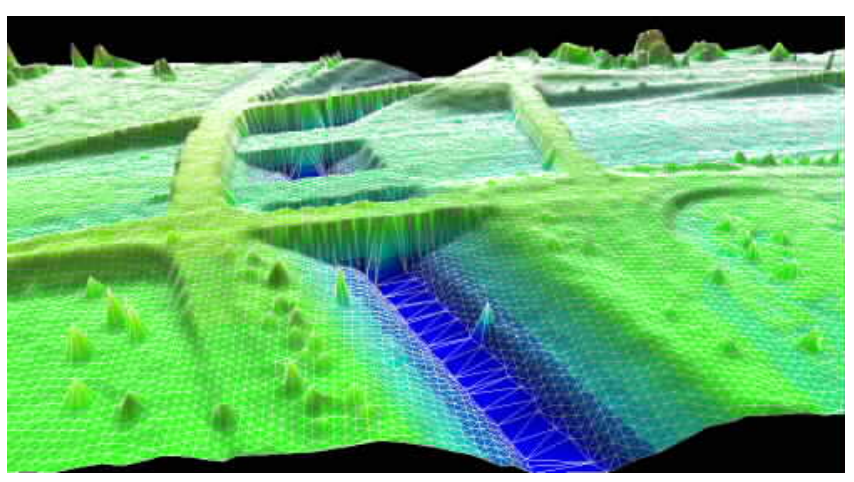

Figure 6. The micro-topography information for the digital elevation model (DEM).

\subsection{Inundated grid cells storing and labeling}

Because much micro-topography information is retained in high-resolution lidar-derived DEM data, many man-made surface features become a part of the DEM; these features include dams, trenches and the surfaces of ponds that cannot be represented on some mid- or low-resolution DEMs (Fig. 6). Suppose that there is a pond surrounded by levees on four-sides. Although the pond becomes inundated during the process of interpolation, it is not actually flooded because the levees do not suffer from the flood. This is a typical false inundation area. Another issue involves ringed mountains; although the elevation of some areas among mountains is lower than flood water level, these areas are not flooded because of the protection of the mountains.

To solve the problem, we can calculate the actual flood extent based on the connectivity principle. However, some judgment methods used to solve the connectivity problem of flat-water and 1-D hydraulic models are based on the entire DEM. These methods cannot be applied to high-resolution DEM data because of the prohibitive DEM size and the computation capability required. Using the seeded region growing method, this produces a difficult amount of data to process, i.e., $8.36 \mathrm{~GB}(22000$ rows $\times 51000$ columns $\times 8$ bytes $\approx 8.36 \mathrm{~GB}$ ); hence, large computer memory sizes would be required to deal with the DEM data of our study area. Moreover, the seeded region growing method is a recursive algorithm with a low efficiency for computations. Thus, problems like recursion might be too deep when dealing with a large amount of data and whereby the stack of a computer can overflow to the extent that computation failures occur. As a result, it is not ideal to employ such neighborhood analysis methods to solve DEM grid connectivity problems when faced with large scales, high resolutions, and enormous amounts of DEM data.

With large amounts of DEM data, it is better to divide the data into strips that can be read easily. As Fig. 7 shows, the DEM data were divided into five strips spatially with each being read one at a time. The results of water-level interpo- 


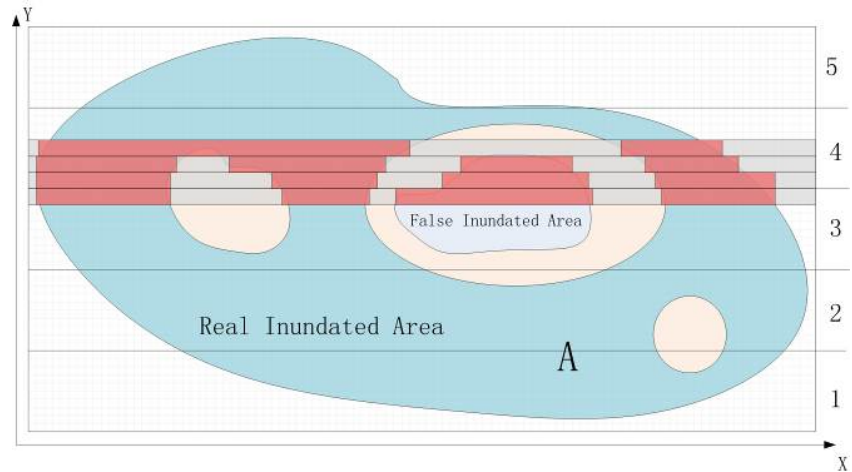

Figure 7. Run-length compressed encoding for the digital elevation model (DEM).

lations were concurrently stored on a raster file with a null value grid equal to the source DEM data. Every time the individual strip water level was interpolated, the result was stored on the corresponding raster file. To process large volumes of DEM data, the memory that was taken up by the previous strip was released before the next data strip was read.

There are two states for every grid cell during DEM grid interpolation; these include un-inundated and mightbe-inundated states. This is typical binary raster data. If we perform run-length compressed encoding to the sequential might-be-inundated DEM grid cells in raster rows, we can mark all the might-be-inundated cells and store them in memory. Run-length encoding is a typical compressed method for raster data (Chang et al., 2006; He et al., 2011), which encodes the cells with the same value in compression. Every run-length only needs to mark the cells with where it starts and where it ends, which reduces the data storage needs remarkably. Figure 7 shows the run-length compressed encoding of the might-be-inundated DEM grid cells. Area A in blue is the real inundation extent where there are three islands. There is a false inundation area inside the middle island. The following are the equations for the run-length data and run-length list on the raster:

$$
\begin{aligned}
& \text { Run length data set }=\{\text { RLList: RLList } \\
& =(\text { RowIndex, RLNum, RLS })\}, \\
& \text { RLS }=\{\text { RL:RL }=(\text { RLIndex, StartCol, EndCol }) .
\end{aligned}
$$

As Eq. (5) shows, the run-length data are mainly comprised of the RLLists on every raster row. The list represents the run-lengths of current raster rows, on which there are RowIndex, RLNum, and RLS. In Eq. (6), RLS consists of all the run-lengths on one raster row, and each run-length carries its RLIndex, StartCol, and EndCol.

\subsection{Connectivity detection principle}

After finishing DEM grid water-level interpolation and storage of run-length compressed encoding of inundated cells

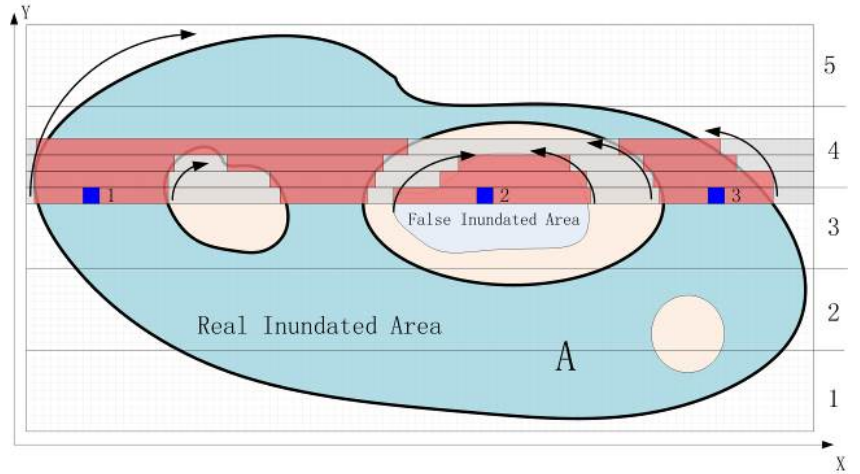

Figure 8. Connectivity detection between the digital elevation model (DEM) grid cells.
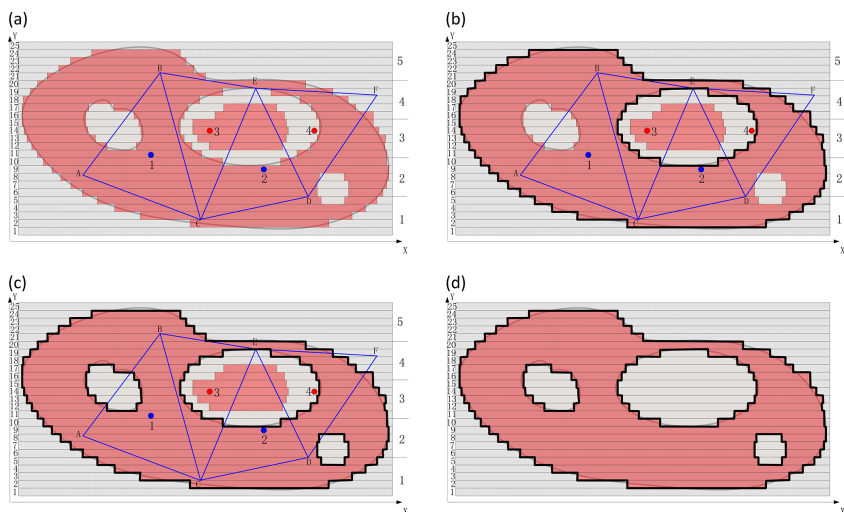

Figure 9. The scheme for run-length boundary tracing and the derived flood extent.

data, the connectivity issue of the DEM grid cells can be solved by run-length boundary tracing technology (Quek, 2000). To prove the connectivity of two inundated cells of the DEM randomly, only a judgment of connectivity for the corresponding run-lengths is needed. Both the right and left borders of a run-length are traced vertically and horizontally. If the two run-lengths are connected, then their borders can be traced to form a closed loop.

In Fig. 8, three inundated cells in a raster field are marked in purple. To prove the connectivity between inundated cell 1 and inundated cell 3 , the run-length of inundated cell 1 (the first run-length on the raster row) and inundated cell 3 (the fourth run-length on the raster row) must be found. If these run-lengths are connected, the boundary trace from the left of the run-length of 1 (as is shown on the graph) will be to the right of 3 as long as it is on the left of 1 .

If the boundary trace from the left of the run-length of inundated cell 1 meets the right of the run-length of inundated cell 3, the cells are connected. Likewise, if the run-length of 1 and the run-length of 2 cannot meet each other by boundary tracing, they are not connected. Based on mutual exclusion, as long as we know that 1 is the real inundation area, all the 
areas connected to 1 are real inundation areas, and all the areas connected to 2 are false inundation areas. As a result, the run-lengths have carried the information of connectivity between inundation grid cells, and the connectivity problem can be worked out through boundary tracing. Compared with the seeded region growing method, this method only requires searches along the run-length borders to prove the connectivity between cells, thus allowing for far faster computation speeds.

\subsection{False inundation area exclusion}

Based on the method mentioned above, we can remove false inundation areas during run-length boundary tracing and obtain an accurate map of flood extent and depth. Figure 9a shows the run-length boundary tracing and flood extent, in which run-lengths are marked with red rectangles. The DEM data only include 25 raster rows, and the model computation mesh is only expressed by four triangles; thus, the runlengths have been simplified. The water-level value of the central point of the mesh element is calculated by model computation, so we can calculate the flood extent by tracing the boundaries of the run-lengths, which can be searched for on the central points of all of computational model elements.

Take Fig. 9a for example, the inundated central point of triangle $\mathrm{ABC}$ can be found on the first run-length on the 11th raster through its spatial coordinate. From the left of this run-length, the outer boundary of the flood extent can be traced (Fig. 9a) and from the right of this run-length, one of the inner boundaries of flood extent can be traced (Fig. 9b). The outer boundary of the entire flood extent can be also traced through boundary tracing of the run-length that can be searched for from the central point of triangle CDE (the 9th row). To avoid repetition of run-length tracing, and to mark real inundated run-lengths, it is important to set two labels along two sides of the run-length to indicate whether a runlength has been traced previously. Run-lengths are marked as traced once one of the sides is traced. Therefore, boundary tracing of the run-length where the central point of triangle $\mathrm{CDE}$ was located was not performed when the run-length of the central point of triangle $\mathrm{ABC}$ had been traced.

After boundary tracing through all the central points of the inundated computational mesh elements, some of the runlengths were only traced by one side, such as rows 5-8 and 12-17 in Fig. 9b. These were located at the islands of the flood extent. Traverse procedures were used through the runlengths to search the islands for the flood extent. Once one side of a run-length was traced (while the other was not), all the islands were found by tracing from the untraced side and performing boundary tracing (Fig. 9c). By this time, there were only two kinds of run-length procedures. One was where each side of the run-length was traced, and the other was where neither side of the run-length was traced. The extent of untraced run-lengths showed the false inundation areas, and the false inundation extent was automatically removed by boundary tracing. Meanwhile, flood extent and depth were interpolated automatically from the traced runlength (Fig. 9d).

\section{Results and discussion}

\subsection{Flood inundation results}

According to the principle mentioned above, we obtained 50 periods worth of flood extent and depth data for the Gongshuangcha detention basin of the Dongting Lake area. Figure 10 (period nos. 10, 30 and 50) shows the comparison between the result from the 2-D hydraulic model and the results from the proposed method mentioned above. The resolution of the 2-D hydraulic model mesh was above $100 \mathrm{~m}$, whereas the proposed method mentioned above interpolates the water level through a $1 \mathrm{~m}$ high-resolution DEM. As a result, although the whole flood extent only differed by a small amount, the distributions of flood depth were very different from each other. The maximum inundation depth calculated by our method was $70 \mathrm{~cm}$ higher than that of the 2-D hydraulic model.

Figure 11 shows the inundation for period no. 50 and its regional enlarged view. In Fig. 11a, the high-resolution aerial remote sensing image taken by the airborne lidar system is shown, and its spatial resolution was $0.3 \mathrm{~m}$. From this image we can see the distribution of farmlands, roads, channels, levees, and houses clearly, among which there are houses that have been constructed along the rivers and levees. Figure $11 \mathrm{~b}$ and c show the 2-D hydraulic model's and our method's regional enlarged view of the inundation area, respectively. The mesh resolution of the 2-D hydraulic model was coarser compared with the geographic features of roads and houses, so the results can only prove that the flood depth of that area was lower while the ponds on the left of the image could not be expressed. It also was not capable of showing the flood conditions for every house. However, with the help of our method, important geographic features can be clearly expressed. From Fig. 11c, it is obvious that not only the flooding condition of channels, ponds, and levees are clearly expressed but also the differences of flood depths between the ridges of paddy fields. In Fig. 11c, there are three linear areas which were not inundated. From Fig. 11d, we can determine that those are levee crests on which houses and roads are being constructed.

\subsection{Inundation area and volume statistics}

We compare the flood extents calculated from the 2-D hydraulic model and the proposed method described above for 50 different periods. In the 2-D hydraulic model, the flood extent was calculated by adding up every inundated triangle's area from the hydraulic computational mesh, while in the proposed method, the flood extent was calculated by summing every real inundated cell area based on $1 \mathrm{~m}$ resolu- 

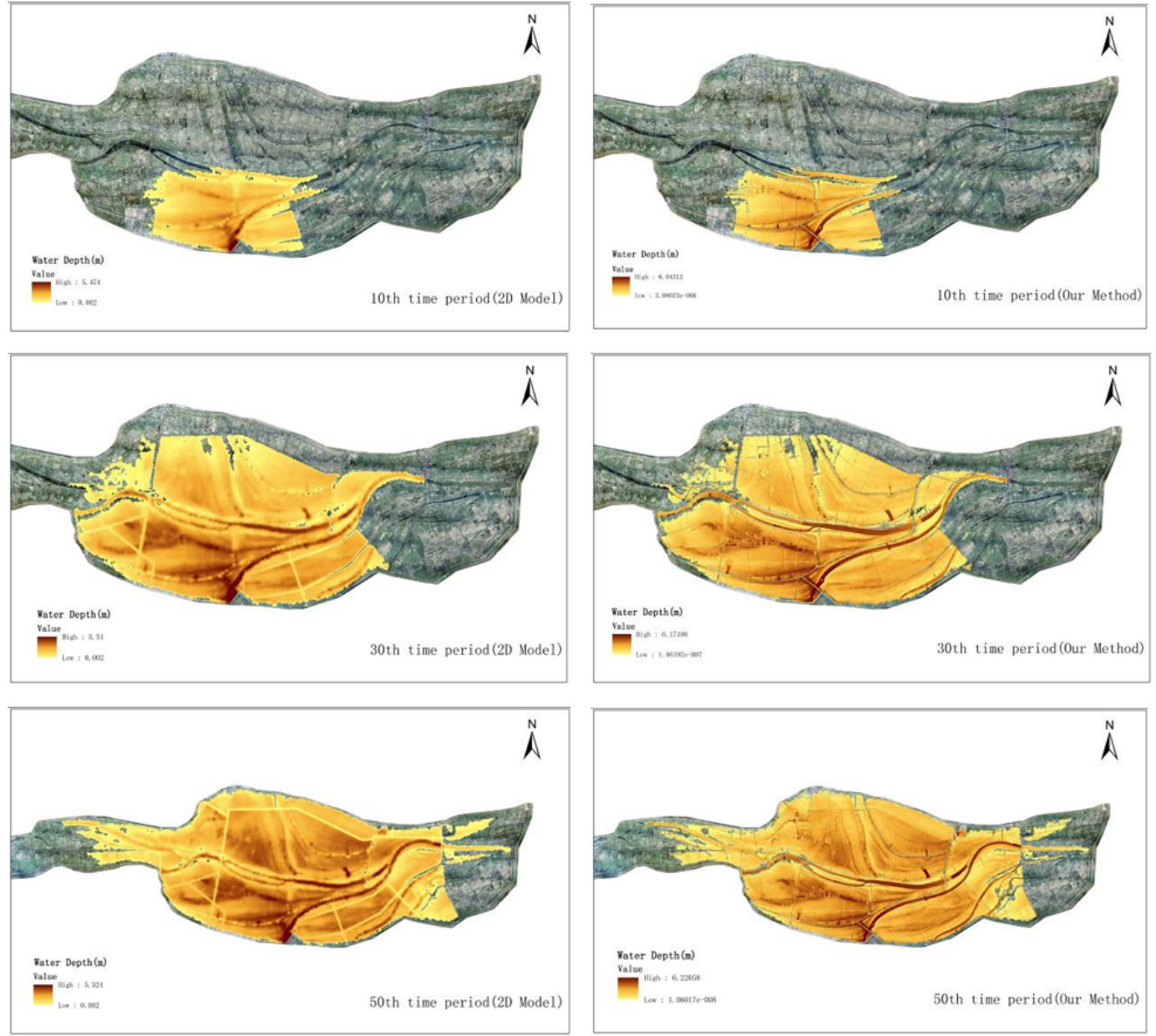

Figure 10. The scheme for the inundation process in the Gongshuangcha detention basin during three different time periods.

tion DEM data. It was expected that the flood extent calculated from the 2-D hydraulic model would be larger than that from the method proposed in this paper (Fig. 12). The 2-D hydraulic model cannot take micro-topography information into full consideration, and many details cannot be shown on the model computational mesh, such as some secondary levees, ponds, and steep slopes. We therefore will get a smaller area result because we can get rid of the parts in the computational mesh whose elevation values are higher than the interpolated water levels.

Among the 50 periods, the flood area calculated by the 2-D hydraulic model surpassed that of our method by $5-17 \%$. In the 50th period, the flood area from the 2-D hydraulic model was $6 \mathrm{~km}^{2}$ larger than that from the proposed method.

As for the inundation volume, the result calculated by the 2-D hydraulic model were smaller than those calculated by our method (Fig. 13). Specifically, according to the previous graphs, the maximum inundation depth and the regional inundation depth calculated by our method were larger than the depths calculated by the 2-D hydraulic model, which means that all of the digital topography could be higher if we em- ploy model computational mesh to express the topography directly. The differences in the results ranged from 3 to $8 \%$, and in the 50th time period, the inundation volume difference was $9.689 \times 10^{6} \mathrm{~m}^{3}$

\subsection{Discussion}

The precision of digital topography is a key factor for flood simulation and analysis. Spatial resolution and vertical precision are both important for mapping the flood extent and depth. Employing high-resolution topography data can make up for errors of a 2-D hydraulic model.

With high-resolution topography data, flood simulation data can be analyzed from the basis of topography and geographic elements because some of the most important microtopography information is accounted for by digital topography data, especially that of levees, ponds, and man-made structures. Once we take the factors from the flood extent and depth map into consideration, we can obtain the results with more precision. 

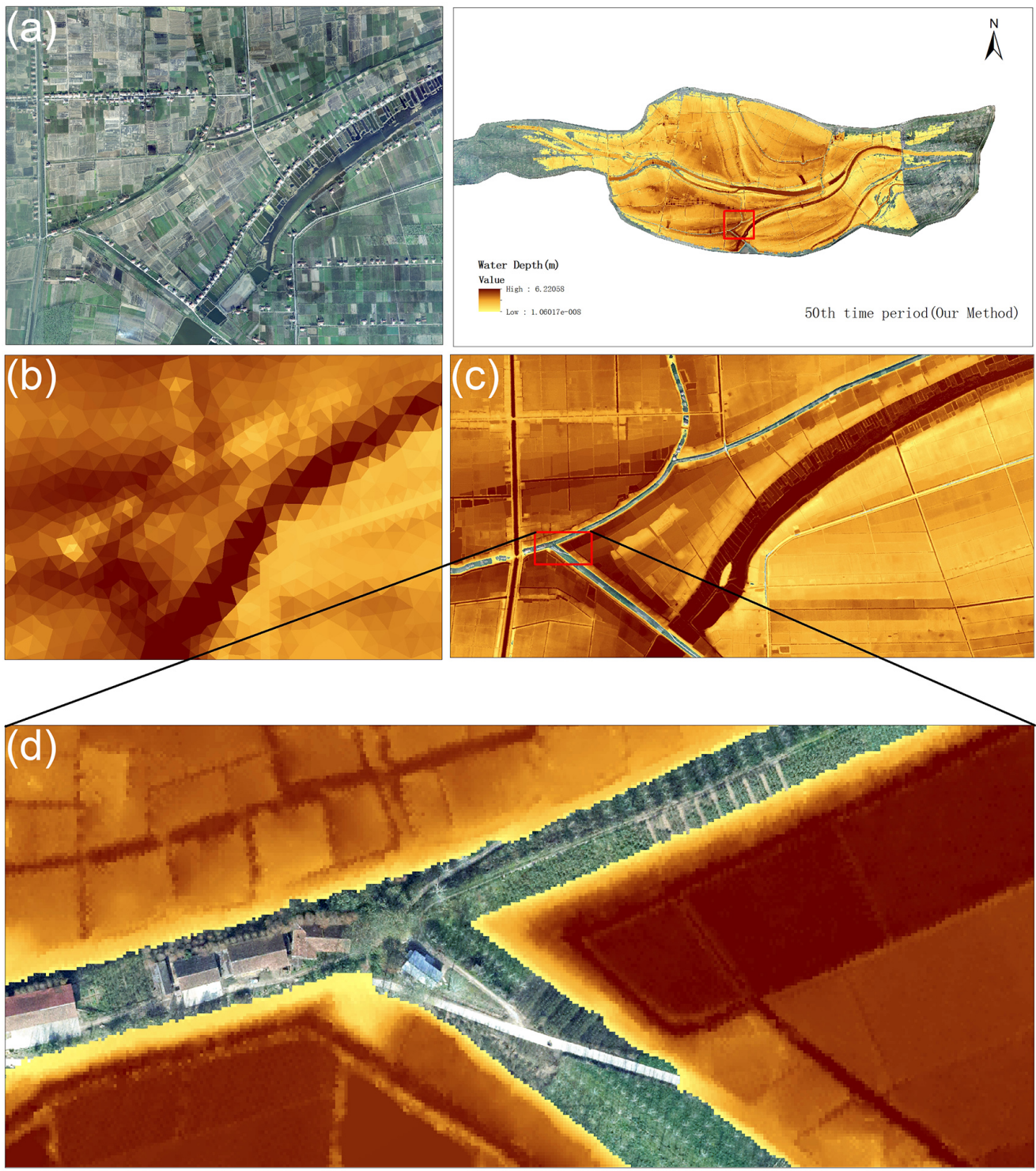

Figure 11. The scheme of the inundation process on the 50th time period and its regional enlarged view. (a) shows the high-resolution aerial remote sensing image taken by the airborne lidar system; (b) and (c) show the 2-D hydraulic model's and our method's regional enlarged view of the inundation area, respectively; (d) shows the levee crests on which houses and roads are being constructed.

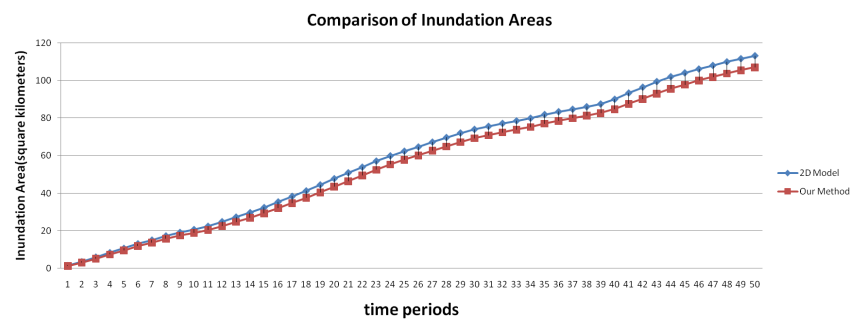

Figure 12. Comparison of inundation areas during different time periods.

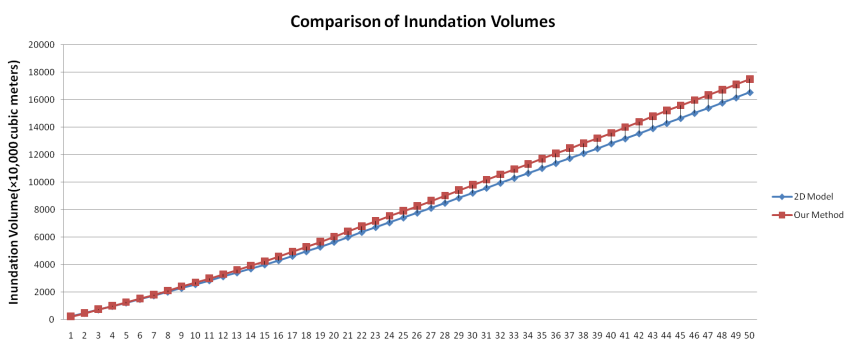

time periods

Figure 13. Comparison of inundation volumes during different time periods. 
However, there are trade-offs involved. With more manmade structures in the high-resolution digital topography, new problems might occur because some false topography information might be involved. For example, airborne lidar point cloud data cannot be distinguished easily from data for channels, bridges over reaches, or viaducts over roads. The redundant information may affect the simulation and analysis results for floodplain flow models. To remove redundant information, later treatments are needed and this might complicate the situation.

\section{Conclusion}

With the help of photogrammetry and remote sensing technology, we can survey the digital terrain of large-scale reaches with high precision. Problems like a loss of topography materials and lack of data accuracy are being gradually solved, which is allowing for progressively greater precision for analyses and assessments of flood disaster risks. The rapid development of lidar technology has especially promoted the acquirement and updating of digital terrain data, and this new data have shown great potential for relevant studies and applications involving flood disaster.

The employment of lidar-derived DEMs to simulate flood routing directly is not realistic because of the complexity of calculations for a hydraulic model with a prohibitively highresolution mesh. Thus, we need to construct a relative coarse model mesh on the basis of high-resolution digital topography. However, much micro-topography information for the high-resolution DEM has been ignored when we deal with flood parameters, which have direct relations to the inundation extent and depth. To address such issues, this paper proposed a method that integrates a 2-D hydraulic model with a high-resolution lidar-derived DEM to simulate floodplain flow. This method can calculate the flood extent and depth with much more precision during floodplain flow modeling. With this kind of digital topography and data for residential houses and public infrastructure, the floods initiated by different events can be analyzed in greater detail. These factors demonstrate the great application potential of our method for predictive flood simulations and accurate assessments of potential losses from flooding events.

Acknowledgements. This work was supported by the fundamental research funds for central public welfare research institutes (grant nos. CKSF2013016/KJ, CKSF2014031/KJ), the National Natural Science Foundation of China (grant nos. 51409021, 41301435), the National Twelfth Five-Year Plan for Science \& Technology Support Program(grant no. 2012BAK10B04), and the Program for New Century Excellent Talents in University (NCET-13-0280).

Edited by: A. Gelfan

\section{References}

Abu-Aly, T. R., Pasternack G. B., Wyrick J. R., Barker R., Massa D., and Johnson T.: Effects of LiDAR-derived, spatially distributed vegetation roughness on two-dimensional hydraulics in a gravelcobble river at flows of 0.2 to 20 times bankfull, Geomorphology, 206, 468-482, 2014.

Apel, H., Aronica, G. T., Kreibich, H., and Thieken, A. H.: Flood risk analyses-how detailed do we need to be?, Nat. Hazards, 49, 79-98, 2009.

Bates, P. D. and De Roo, A. P. J.: A simple raster-based model for flood inundation simulation, J. Hydrol., 236, 54-77, 2000.

Belikov, V. V. and Semenov, A. Y.: New NonSibson Interpolation on Arbitrary System of Points in Euclidean Space. Proceedings of 15th World Congress on Scientific Computation Modeling and Applied Mathematics, August 1997, Berlin 1997.

Belikov, V. V. and Semenov, A. Y.: Non-Sibsonian interpolation on arbitrary system of points in Euclidean space and adaptive isolines generation, Appl. Numer. Math., 32, 371-387, 2000.

Brown, J. D., Spencer, T., and Moeller, I.: Modeling storm surge flooding of an urban area with particular reference to modeling uncertainties: a case study of Canvey Island, United Kingdom, Water Resour. Res., 43, W06402, doi:10.1029/2005WR004597, 2007.

Chang, C. C., Lin, C. Y., and Wang, Y. Z.: New image steganographic methods using run-length approach, Inform. Sciences, 176, 3393-3408, 2006

Chen, A. S., Evans, B., Djordjevic, S., and Savic, D. A.: Multilayered coarse grid modelling in 2D urban flood simulations, J. Hydrol., 470-471, 1-11, 2012a.

Chen, A. S., Evans, B., Djordjevic, S., and Savic, D. A.: A coarsegrid approach to representing building blockage effects in $2 \mathrm{D}$ urban flood modelling, J. Hydrol., 426, 1-16, 2012 b.

Costabile, P. and Macchione, F.: Enhancing river model set-up for 2-D dynamic flood modelling, Environ. Modell. Softw., 67, 89107, 2015.

Costabile, P., Macchione, F., Natale, L., and Petaccia, G.: Flood mapping using LIDAR DEM. Limitations of the 1-D modeling highlighted by the 2-D approach, Nat. Hazards, 77, 181-204, 2015.

CWRC (Changjiang Water Resources Commission): Comprehensive Treatment Planning of Dongting Lake Area, Changjiang Water Resources Commission, China, 2008.

Dottori, F., Di Baldassarre, G., and Todini, E.: Detailed data is welcome, but with a pinch of salt: Accuracy, precision, and uncertainty in flood inundation modeling, Water Resour. Res., 49, 6079-6085, 2013

Fewtrell, T. J., Duncan, A., Sampson, C. C., Neal, J. C., and Bates, P. D.: Benchmarking urban flood models of varying complexity and scale using high resolution terrestrial LiDAR data, Phys. Chem. Earth, 36, 281-291, 2011.

Gichamo, T. Z., Popescu, I., Jonoski, A., and Solomatine, D.: River Cross-section extraction from the ASTER global DEM for flood modeling, Environ Modell. Softw., 31, 37-46, 2012.

Guinot, V.: Multiple porosity shallow water models for macroscopic modelling of urban floods, Adv. Water Resour., 37, 40-72, 2012

He, Z., Sun, W., Lu, W., and Lu, H.: Digital image splicing detection based on approximate run length, Pattern Recogn. Lett., 32, 1591-1597, 2011. 
Mandlburger, G., Hauer, C., Höfle, B., Habersack, H., and Pfeifer, N.: Optimisation of LiDAR derived terrain models for river flow modelling, Hydrol. Earth Syst. Sci., 13, 1453-1466, doi:10.5194/hess-13-1453-2009, 2009.

Marks, K. and Bates, P.: Integration of high-resolution topographic data with floodplain flow models, Hydrol. Process., 14, 21092122, 2000.

McMillan, H. K. and Brasington, J.: Reduced complexity strategies for modelling urban floodplain inundation, Geomorphology, 90, 226-243, 2007.

Meesuk, V., Vojinovic, Z., Mynett, A. E., and Abdullah, A. F.: Urban flood modelling combining top-view LiDAR data with ground-view SfM observations, Adv. Water Resour., 75, 105117, 2015.

Moore, M. R.: Development of a high-resolution 1D/2D coupled flood simulation of Charles City, Iowa, MS thesis, University of Iowa, Iowa City, Iowa, 49-68, 2011.

MWR (Ministry of Water Resources): Report on the Feasibility of the Flood Control Project of Qianliang Lake, Gongshuangcha and East Datong Lake of Dongting Lake Areas, Ministry of Water Resources, Beijing, China, 2009.

Neal., J. C., Bates, P. D., Fewtrell, T. J., Hunter, N. M., and Wilson, M. D.: Distributed whole city water level measurements from the Carlisle 2005 urban flood event and comparison with hydraulic model simulations, J. Hydrol., 368, 42-55, 2009.

Neal, J. C., Fewtrell, T. J., Bates, P. D., and Wright, N. G.: A comparison of three parallelisation methods for 2D flood inundation models, Environ. Modell. Softw., 25, 398-411, 2010.

Quek, F. K. H.: An algorithm for the rapid computation of boundaries of run-length encoded regions, Pattern Recogn., 33, 16371649, 2000.

Sampson, C. C., Fewtrell, T. J., Duncan, A., Shaad, K., Horrit, M. S., and Bates, P. D.: Use of terrestrial laser data to drive decimetric resolution urban inundation models, Adv. Water Resour., 14, 1-17, 2012.

Sanders, B. F.: Evaluation of on-line DEMs for flood inundation modeling, Adv. Water Resour., 30, 1831-1843, 2007.

Sanders, B. F., Schubert, J. E., and Gallegos, H. A.: Integral formulation of shallow-water equations with anisotropic porosity for urban flood modeling, J. Hydrol., 362, 19-38, 2008.
Sanders, B. F., Schubert, J. E., and Detwiler, R. L.: ParBreZo: A parallel, unstructured grid, Godunov-type, shallow-water code for high-resolution flood inundation modeling at the regional scale, Adv. Water Resour., 33, 1456-1467, 2010.

Schubert, J. E. and Sanders, B. F.: Building treatments for urban flood inundation models and implications for predictive skill and modeling efficiency, Adv. Water Resour., 41, 49-64, 2012.

Schubert, J. E., Sanders, B. F., Smith, M. J., and Wright, N. G.: Unstructured mesh generation and landcover-based resistence for hydrodynamic modeling of urban flooding, Adv. Water Resour., 31, 1603-1621, 2008.

Shaad, K.: Surface water flooding: analysis and model development, MS thesis, Brandenburg University of Technology, Cottbus, Germany, 2009.

Sibson, R.: A brief description of the natural neighbor interpolant, in: Interpreting Multivariate Data, John Wiley \& Sons, Chicester, 21-36, 1981.

Sukumar, N., Moran, B., and Belikov, V. V.: Natural neighbour Galerkin methods, Int. J. Numer. Meth. Eng., 50, 1-27, 2001.

Vacondio, R., Dal Palu, A., and Mingnosa, P.: GPU-enhanced Finite Volume Shallow Water solver for fast flood simulations, Environ. Modell. Softw., 57, 60-75, 2014.

Werner, M. G. F.: Impact of Grid Size in GIS Based Flood Extent Mapping Using a 1D Flow Model, Phys. Chem. Earth Pt. B, 26, 517-522, 2001.

Yu, D.: Parallelization of a two-dimensional flood inundation model based on domain decomposition, Environ. Modell. Softw., 25, 935-945, 2010.

Yu, D. and Lane, S. N.: Urban fluvial flood modelling using a twodimensional diffusion-wave treatment, part 1: mesh resolution effects, Hydrol. Process., 20, 1541-1565, 2006 a.

$\mathrm{Yu}$, D. and Lane, S. N.: Urban fluvial flood modelling using a two-dimensional diffusion-wave treatment, part 2: development of a sub-grid-scale treatment, Hydrol. Process., 20, 1541-1565, 2006b.

Yu, D. and Lane, S. N.: Interactions between subgrid-scale resolution, feature representation and grid-scale resolution in flood inundation modelling, Hydrol. Process., 25, 36-53, 2011. 